\title{
93. Organic Geochemistry of a 200-meter Core Sample from Lake Biwa. II
}

\section{Vertical Distribution of Mono- and Di-caboxylic Acids and Polynuclear Aromatic Hydrocarbons}

\author{
By Ryoshi Ishiwatari and Takahisa HANYA \\ Department of Chemistry, Faculty of Science, Tokyo Metropolitan University, \\ Setagaya, Tokyo
}

(Comm. by Kenjiro Kimura, M. J. A., June 3, 1975)

The presence of fatty acids such as mono- and di-carboxylic acids in the core sample from Lake Biwa was established in the previous paper (Ishiwatari and Hanya 1973). Since these compounds are thought to have originated from aquatic organisms as well as from the soils surrounding the lake, there is a possibility that the quantitative determination of these compounds offers information on the biological activity in the lake water and of the degree of the relative contribution of organic materials in and out of the lake at the time of sediment formation. In this connection, it is also interesting to determine polynuclear aromatic hydrocarbons including perylene, because the latter is believed to be derived from the terrestrial soil (Orr and Grady 1967; Aizenshtat 1973) and so is expected to inform us as to the contribution of soil-derived organic materials to the sediment.

In this study, mono- and di-carboxylic acids and polynuclear aromatic hydrocarbons in the 200-meter core sample from Lake Biwa were determined quantitatively with the discussion of their origin and the changes in contribution of the lake-derived and the soilderived organic materials through the core.

Materials and methods. A wet sample (2-9 $\mathrm{g}$ by dry weight) was taken for analysis from the core at different depth. Detailed description of analysis will be given elsewhere.

Monocarboxylic acids, dicarboxylic acids and polynuclear aromatic hydrocarbons were identified on a Shimazu-LKB 9000 gas chromatograph-mass spectrometer on the basis of mass spectra and mass chromatography. Quantitative determination of monocarboxylic acids was achieved on a Shimazu GC-1C gas chromatograph with a flame ionization detector, and that of dicarboxylic acids was conducted by mass chromatography at m/e 98 or M-31 ( $\mathrm{M}=$ molecular weight). For a quantitative determination of polynuclear aromatic 


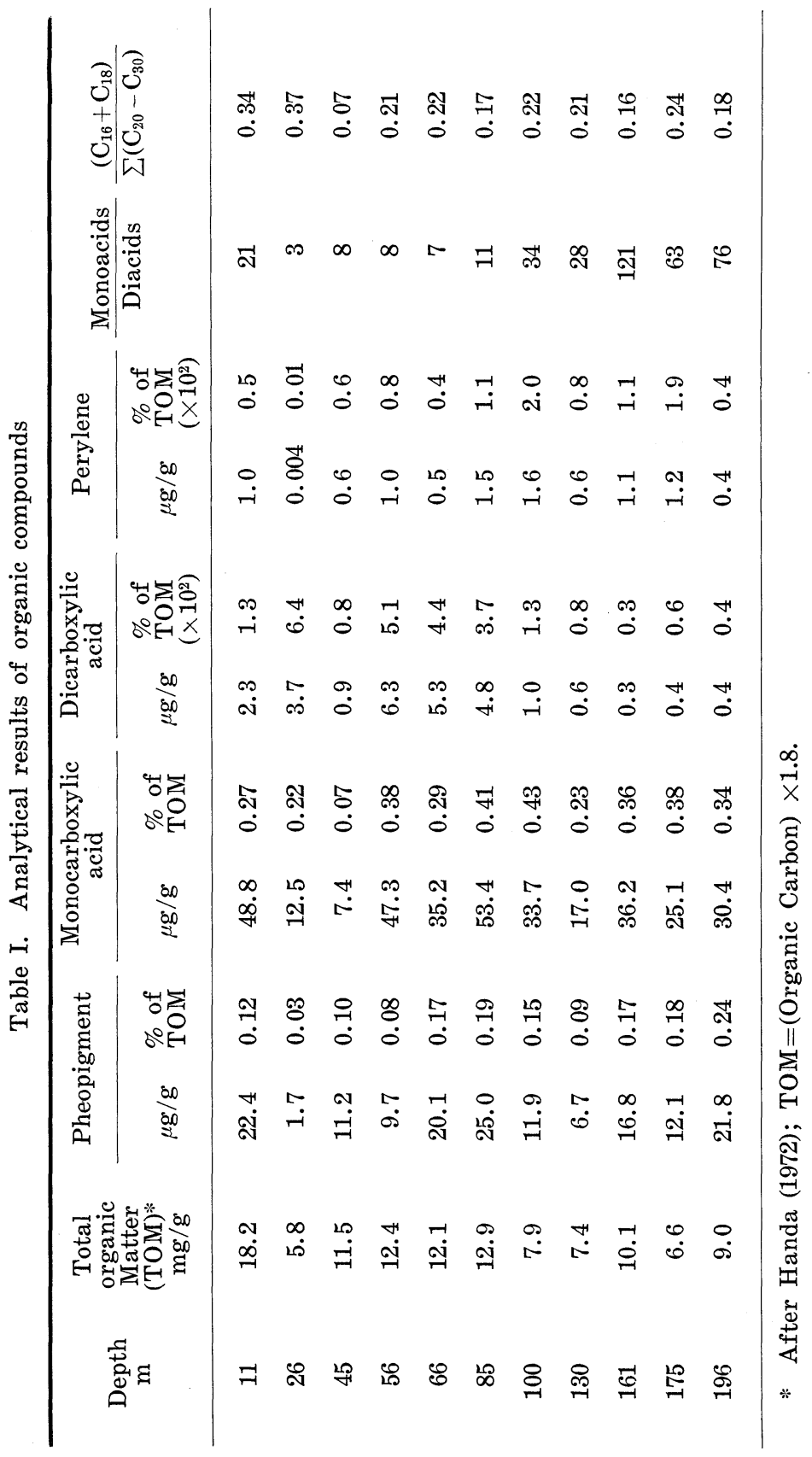




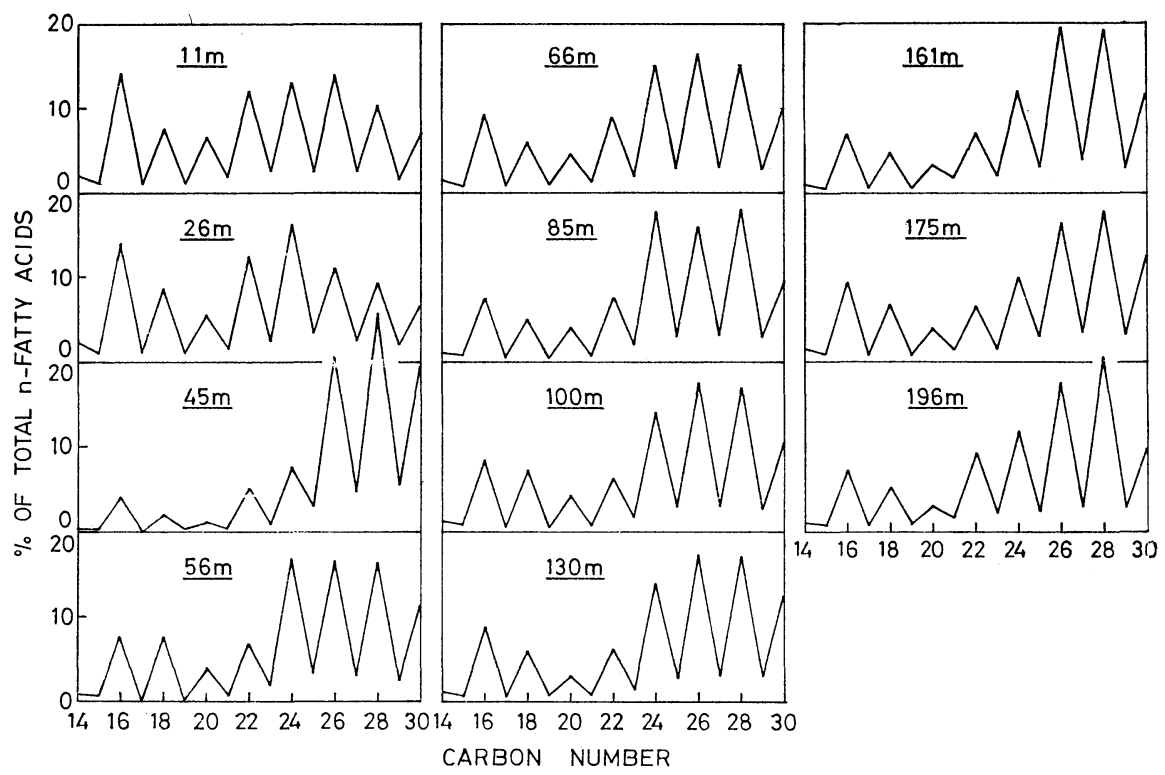

Fig. 1. Vertical variation of normal monocarboxylic acid distribution.

hydrocarbons, a mass chromatography was run at different $\mathrm{m} / \mathrm{e}$ corresponding to this molecular ion. The quantitative result was expressed as a value equivalent to perylene.

Results. Table I shows the results of our analysis and the data on the total organic matter as reported by Handa (1972).

The monocarboxylic acids amount to $0.07-0.4 \%$ of the total organic matter. The values are similar to those for a younger lacustrine sediment sample $(0.2-0.7 \%$ for Lake Haruna; unpublished result). Fig. 1 gives the vertical variation in normal monocarboxylic acid distribution through the core. The normal monocarboxylic acids show a marked even carbon predominance which is seen in most biosynthetic lipids. As reported before (Ishiwatari and Hanya 1973), there are two maxima at $\mathrm{C}_{16}$ and $\mathrm{C}_{24}-\mathrm{C}_{28}$ acids in their distribution. It is interesting to note the significant difference in the monocarboxylic acid distribution among samples. Although this may be due to the differences in precursory materials and chemical conditions after their burial, a more detailed discussion can not be made at the moment. A striking characteristic of the distribution is the relatively high abundance of $\mathrm{C}_{20}-\mathrm{C}_{30}$ acids as compared with those having shorter carbon chains. The distribution pattern is clearly different from those for the sediment samples from Lake Haruna (unpublished result) and apparently the difference is the result of the contribution of soil-derived organic materials. 


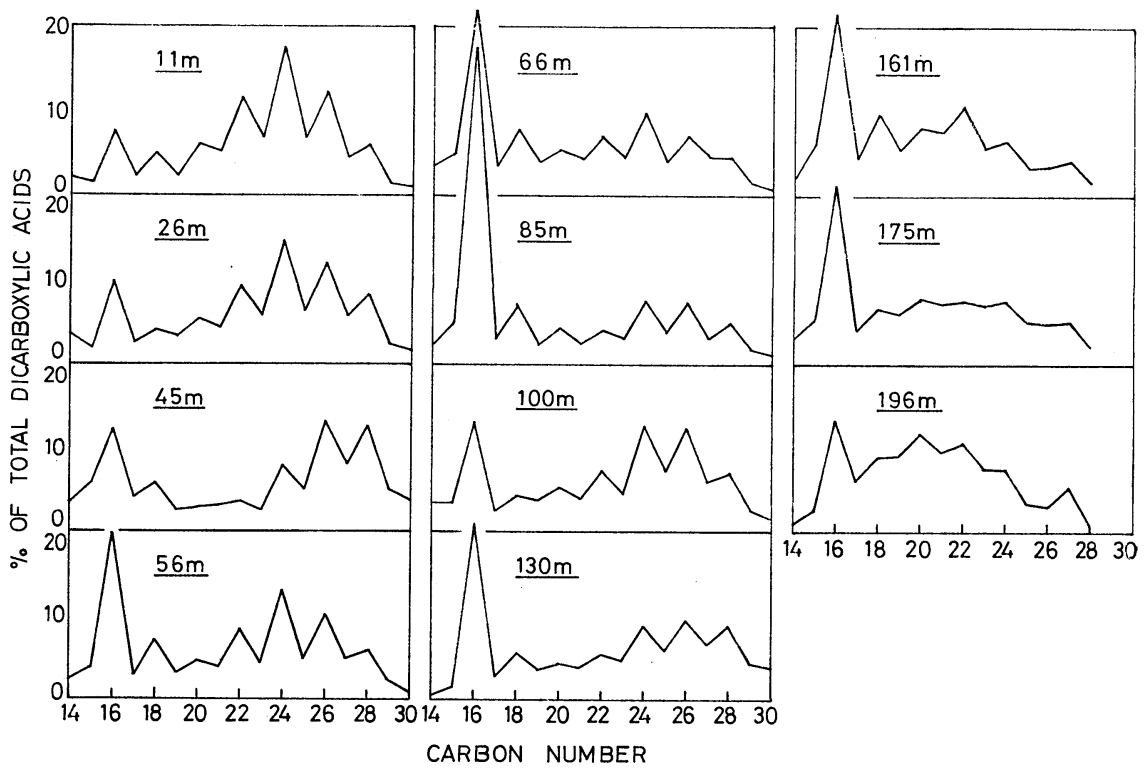

Fig. 2. Vertical variation of $\alpha, \omega$-dicarboxylic acid distribution.

The presence of $\mathrm{C}_{14}-\mathrm{C}_{30} \alpha$, $\omega$-dicarboxylic acids in the sample was established. The $\mathrm{C}_{12}$ to $\mathrm{C}_{32} \alpha$, $\omega$-dicarboxylic acids are present in an ancient sediment (Hug et al. 1967; Douglas et al. 1971), $\mathrm{C}_{16}-\mathrm{C}_{24} \alpha$, $\omega$-dicarboxylic acids in a Recent freshwater lake sediment (Eglinton et al. 1968) and $\mathrm{C}_{14}-\mathrm{C}_{30} \alpha, \omega$-dicarboxylic acids in Lake Haruna (unpublished result). Therefore, the range of dicarboxylic acids for our samples agrees well with those reported.

Table I gives the total amount of dicarboxylic acids, being $0.003-$ $0.06 \%$ of the total organic matter and $1 / 3$ to $1 / 120$ of the total monocarboxylic acids. Fig. 2 shows the dicarboxylic acid distribution for the samples. The distribution patterns have two maxima at the $\mathrm{C}_{16}$ and $\mathrm{C}_{24}-\mathrm{C}_{28}$ regions, which suggests a close relationship in origin between mono- and dicarboxylic acids.

As expected, perylene is the most abundant of all polynuclear aromatic hydrocarbons (Table I). The amount of perylene is generally higher than those for Lake Haruna $\left(0.1-0.7 \times 10^{-2} \%\right.$ of TOM; unpublished result) and those for a near-shore sediment $(0.1-0.9 \times$ $10^{-2} \%$ of TOM ; Aizenshtat 1973). Blumer (1961) reported two benzpyrene isomers and 12 other polynuclear aromatic hydrocarbons in soils. Seven of them (phenanthrene, fluoranthene, pyrene, chrysene, perylene, anthracene and benzpyrene) were found for our samples. However, benzpyrene is not so abundant in our samples as in soils reported by Blumer (1961) $(0.04-1.3 \mu \mathrm{g} / \mathrm{g})$. 
Discussion. Pheopigment is a degradation product of chlorophyll pigment which is mainly composed of pheophytin and/or pheophorbide. The amount of pheopigment in a sediment may be related to chlorophyll production in the water above the sediment, because Lorenzen (1974) has found that the pigment content of a sediment off the southwestern coast of Africa is directly related to surface water chlorophyll content. For the present case, the contribution of the surrounding soils to the sediment must be taken into account.

The pheopigment/TOM was calculated to estimate that extent of contribution of phytoplankton residues in the sediment samples. As already shown in Table 1, the ratio has a broad peak around the $85 \mathrm{~m}$ layer and the highest value in the $196 \mathrm{~m}$ layer. The highest value of pheopigment/TOM in the $196 \mathrm{~m}$ layer is in agreement with the result of the observation of microfossils made by Kadota (1973) who found green algae to be most abundant in that layer. However, relatively high values around the $85 \mathrm{~m}$ layer do not agree with Kadota's observation. In addition, pheopigments were found in the layers where no green algae residues were found. This may be explained by the presence of fossil diatom residues in all layers (Mori unpublished result).

According to Nakai (1972), the $\delta^{13} \mathrm{C}$ values of organic carbon in the sediment samples range from -31 to $-38 \%$, which he explained by the large contribution of plankton residue to the sedimentary organic materials. However, no clear relationship is observed between $\delta^{13} \mathrm{C}$ values and pheopigment/TOM. A possible reason is that the pheopigment content of the sediment samples is governed by very complicated factors such as populations of phytoplankton in the water above the sediment and the conditions of preservation of chlorophyll pigment after burial.

Normal monocarboxylic acids in a sediment are considered to be derived from aquatic organisms and soils, that is $\mathrm{C}_{14}-\mathrm{C}_{18}$ acids are mainly derived from aquatic organisms and $\mathrm{C}_{20}-\mathrm{C}_{30}$ acids from soil waxes. In fact, we observed that monocarboxylic acids in the soils surrounding Lake Haruna range from $\mathrm{C}_{14}$ to $\mathrm{C}_{30}, \mathrm{C}_{20}-\mathrm{C}_{30}$ acids being more abundant than those in the sediment samples. Therefore, the ratio of $\mathrm{C}_{16}$ plus $\mathrm{C}_{18}$ acids to $\mathrm{C}_{20}-\mathrm{C}_{30}$ acids is expected to be a good index of the contribution of lake-derived organic materials to the sedimentary organic materials. As shown in Table $\mathrm{I}$, the ratio ranges from 0.07 to 0.37 and shows a variation in a rather wide range. The values are lower than those for Lake Haruna (0.4-1.2; unpublished result). This may indicate the relatively large contribution of soilderived organic materials throughout the core, although a possibility of post-depositional change in the relative distribution of monocar- 
boxylic acids can not be excluded. A linear relationship seems to be present between $\left(\mathrm{C}_{16}+\mathrm{C}_{18}\right) / \sum\left(\mathrm{C}_{20}-\mathrm{C}_{30}\right)$ and $\delta^{13} \mathrm{C}$ of organic materials, indicating that $\delta^{13} \mathrm{C}$ is closely related to the contribution of lake-derived organic materials as a whole.

The presence of perylene indicates the contribution of soilderived organic materials to the sediment samples. However, no reverse relationship is seen between $\left(\mathrm{C}_{16}+\mathrm{C}_{18}\right) / \sum\left(\mathrm{C}_{20}-\mathrm{C}_{30}\right)$ and perylene/TOM, although the relationship is observed for the samples from Lake Haruna. No satisfactory explanation for this can be presented at present.

The origin and significance of polynuclear aromatic hydrocarbons other than perylene are unknown. In the case of Lake Haruna, the amount of such materials in the sediment samples decreases rapidly in the layers $0.5 \mathrm{~m}$ from the surface and then becomes practically constant. This fact and the distribution pattern for the present samples indicate the difference in origin between perylene and the other hydrocarbons.

For the origin of dicarboxylic acids, Haugh et al. (1967) considered that it is partly due to the bacterial omega oxidation of monocarboxylic acid. Eglinton et al. (1968) considered on the basis of the parallel distribution of the chain lengths of the diacids and $\omega$-hydroxy acids that they are more likely derived from the oxidation of the $\omega$-hydroxy acids. Since a close relationship in origin seems to be present between mono- and di-carboxylic acids for our samples, the present authors are tempted to consider that the dicarboxylic acids have been formed as a result of bacterial oxidation immediately after their burial.

\section{References}

Aizenshtat, Z.: Geochim. Cosmochim. Acta, 37, 559 (1967).

Blumer, M.: Science, 134, 474 (1961).

Dougas, A. G., M. Blumer, G. Eglinton, and K. Douraghi-Zaden: Tetrahedron, 27, 1071 (1971).

Eglinton, G., D. H. Hunneman, and K. Douraghi-Zadeh: Terahedron, 24, 5929 (1968).

Handa, N.: Proc. Japan Acad., 48, 510 (1972).

Haug, P., H. K. Schnoes, and A. L. Burlingame: Science, 158, 772 (1967).

Ishiwatari, R., and T. Hanya: Proc. Japan Acad., 49, 731 (1973).

Kadota, S.: Jap. J. Limnol., 34, 103 (1973).

Lorenzen, C. J.: The Black Sea-Geology, Chemistry and Biology (E. T. Degens: and D. A. Ross ed.), p. 426. Amer. Assoc. Petroleum Geol. (1974).

Mori, S.: Personal communication.

Nakai, N.: Japan Acad., 48, 516 (1972).

Orr, W. L., and J. R. Grady: Geochim. Cosmochim. Acta., 31, 1201 (1967).

Rehage, R., and E. Stenhagen: Arkiv Kemi, 14, 497 (1959). 